\title{
ANA LYDIA PLURAVEGA: \\ UNIDAD Y MULTIPLICIDAD CARIBEÑAS EN LA OBRA DE ANA LYDIA VEGA
}

POR

\author{
ANÍBAL GONZÁLEZ \\ The University of Texas at Austin
}

Desde ese instante, senti a mi alrededor y en mi oscurocuerpo una invisible, intangible pululación.

-Borges, "El jardín de senderos que se bifurcan”

De entre los nuevos escritores y escritoras surgidos en Puerto Rico durante la década del setenta, a pocos se les puede aplicar el calificativo de brillante con mayor propiedad que a Ana Lydia Vega. Dueña de un estilo flexible, ingenioso y proteico sólo comparable al de Luis Rafael Sánchez, Vega ha logrado, con solamente publicar dos libros y medio, establecer una fuerte presencia en el panorama de la literatura puertorriqueña actual. Su primer libro de cuentos, Virgenes y mártires (1981), escrito en colaboración con otra notable escritora de su generación, Carmen Lugo Filippi, llamóla atención tanto por su originalidad y su calidad literaria como por sus planteamientos feministas. En 1983, Vega "debutócomo solista" con el volumen de cuentos Encancaranublado, el cual había sido premiado en el Certamen de Casa de las Américas de 1982; y a finales de 1987 salió publicado en Buenos Aires su libro de cuentos detectivescos titulado Pasión de historia. ${ }^{1}$

Noes exagerado, entonces, a pesar de su carácter todavia incipiente, hablar de la obra de Ana Lydia Vega. Los textos de Vega, circunscritos por ahora a los géneros del cuento, el ensayo periodístico, y el guión de cine, ${ }^{2}$ exhiben una gran densidad conceptual, así como una disposición a confrontarse con los más importantes temas y problemas de la tradición literaria caribeña, que contrapesa sobradamente la brevedad y el carácter algo disperso de éstos. De hecho, según espero mostrar en este trabajo, la fragmentación, la dispersión y la búsqueda de

\footnotetext{
1 Ana Lydia Vega y Carmen Lugo Filippi, Virgenes y mártires (Río Piedras: Editorial Antillana, 1981); Ana Lydia Vega, Encancaranublado y otros cuentos de naufragio (Río Piedras: Editorial Antillana, 1983); Ana Lydia Vega, Pasion de historia y otras historias de pasión (Buenos Aires: Ediciones de la Flor, 1987).

${ }^{2}$ El guión de cine al que me refiero es el de la exitosa película puertorriqueña La gran fiesta, estrenada en 1986, el cual Vega escribí junto con el director del filme, Marcos Zurinaga.
} 
unidad, de consenso, no son sólo rasgos de la producción literaria de Ana Lydia Vega, sino que configuran además su núcleo temático más importante. Mi lectura se va a concentrar en sus dos primeros libros, Vírgenes y mártires y Encancaranublado, pues en ambos Vega ofrece una reflexión sostenida sobre la identidad antillana tanto a nivel colectivo como individual.

Como muchos actuales escritores y escritoras puertorriqueñas, Vega considera que Puerto Rico es antes que nada una nación caribeña, luego una nación hispanoamericana, y sólo accidental y temporariamente una posesión norteamericana. ${ }^{3}$ Tratar de definir la identidad puertorriqueña en función de una más amplia identidad cultural caribeña, sin embargo, implica confrontarse con un problema que ha ocupado lainteligencia y laimaginación de prácticamente todos los grandes escritores caribeños, desde Cuba hasta Trinidad, desde hace por lo menos un siglo: se trata de la cuestión de la unidad o multiplicidad de la región caribeña. En efecto, la propia identidad cultural del Caribe, así como su integridad regional, están en tela de juicio y suscitan hondos problemas de epistemología sociológica. ¿Cómo podemos conocer al Caribe si no sabemos si es uno o es muchos lugares, si no sabemos cuáles son sus fronteras geográficas, si no podemos ponernos de acuerdo en cuanto a sus rasgos unificadores? Como señala Sidney Mintz:

Examinada desde una perspectiva racial, demográfica o sociocultural, la región caribeña es siempre diferenciada y compleja. Cualquier intento de evaluar la experiencia de los pueblos afrocaribeños desde una perspectiva generalizadora tiene que desembocar en la desesperacion. ${ }^{4}$

Esa desesperación es, según veremos, algo contra lo cual Ana Lydia Vega lucha continuamente en sus cuentos caribeños, al tratar de llegar, como los personajes alegóricos del Arroz y la Habichuela en el último relato de Encancaranublado, "al consenso sin plebiscito". 5

Pero antes de examinar detalladamente cómo Vega se enfrenta a la problemática de Puerto Rico y el Caribe, conviene hacer un paréntesis genealógico para rememorar al precursor de los intentos actuales de situar a Puerto Rico en su contexto caribeño. Me refiero, por supuesto, a Luis Palés Matos. En todos los cuentos de Encancaranublado, y en algunos de Vírgenes y mártires, hallamos de hecho un diálogo que a veces se torna en abierta polémica con ese patriarca de la poesía puertorriqueña y con su discurso patriarcal.

${ }^{3}$ He desarrollado estas ideas con mayor extension en mi ensayo "Ballad of the Two Poets: Nicolás Guillén and Luis Palés Matos", en Callaloo. A Journal of Afro-American and African Arts and Letters 2 (Nicolás Guillén: A Special Issue) (Primavera, 1987) 285-301. "Sidney W. Mintz, "The Caribbean Region". Slavery, Colonialism, and Racism (Nueva York: W. W. Norton \& Co., Inc., 1974), 46-46. La traducción es mía.

${ }^{5}$ Vega, Encancaranublado 140. 
En su libro de poemas afroantillanos, Tuntún de pasaygrifería (1937), Palés produce un discurso cuidadosamente razonadoen el cual propone una visión del Caribe como un sistema sociocultural coherente. Partiendo de las ideas de Oswald Spengler en La decadencia de Occidente (1917) suplementadas con las observaciones de Fernando Ortiz en Los negros brujos (1906), Palés ve al Caribe -particularmente al Caribe Hispánico- como la cuna de una nueva cultura que surge de la fusión de las culturas europeas y africanas en el suelo antillano. Esta nueva cultura mulata sería, según Palés, una síntesis en la cual los ciclos de la historia y sociedad blanca encajarían con los de los negros en un armonioso -y hegeliano- ciclo de ciclos. Siguiendo los apuntes de Ramiro Guerra en Azúcar y población en el Caribe (1972), Palés concibe al ingenio y al proceso de la producción azucarera como el crisol para este encuentro y fusión de culturas. $\mathrm{El}$ ingenio transforma la noción blanca del tiempo como una progresión lineal y secularizada, en una noción cíclica vinculada a los ritmos de la producción azucarera. De esta forma, el ingenio acerca la temporalidad del blanco a la de los negros, la cual Palés, siguiendo a Spengler, considera que es inherentemente circular o cíclica, como corresponde a una cultura supuestamente "primitiva" con un sentido religioso de la existencia. Como podría esperarse, la expresión cultural por excelencia de esa síntesis, de ese engranaje de ciclos y ritmos, se encuentra en la música y en el baile afroantillanos: la música marca el compás del tiempo litúrgico, sagrado, de los negros, mientras que el baile imita en sus gestos los movimientos del cuerpo al trabajar en el proceso de producción azucarera. Así lo expresan en sus sinestesias los memorables versos de "Majestad negra":

\footnotetext{
Culipandeando la Reina avanza y de su inmensa grupa resbalan meneos cachondos que el gongo cuaja en ríos de azúcar y de melaza. Prieto trapiche de sensual zafra, el caderamen masa con masa, exprime ritmos, suda que sangra, y la molienda culmina en danza. ${ }^{6}$
}

Para Palés, el Caribe encuentra su unidad subyacente en la nueva cultura mulata que la zona alberga. Cultura que Palés alegoriza en la figura femenina de la "mulata-antilla", en la cual se resuelven armoniosamente los más contradictorios impulsos, evocando el tópico clásico de concordia discors:

Eres ahora, mulata, todo el mar y la tierra de mis islas.

\footnotetext{
${ }^{6}$ LuisPalés Matos, "Majestad Negra" enObras: 1914-1959. Tomol: Poesía, edición, prólogo, cronologia, notas y variantes al cuidado de Margot Arce de Vázquez (Río Piedras: Editorial de la Universidad de Puerto Rico, 1984) 485.
} 


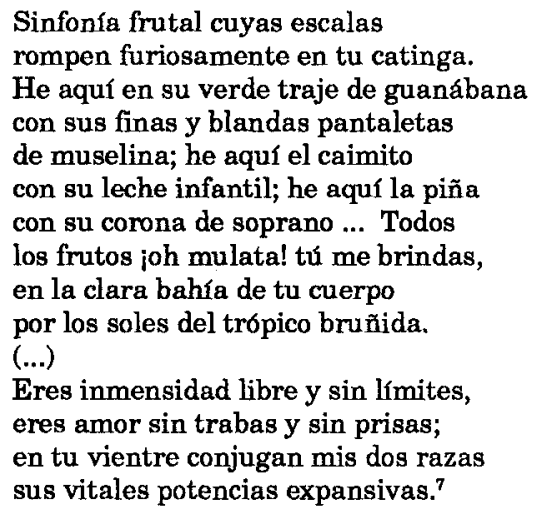

Como Vasconcelos en La raza cósmica (1925), Palés produce una visión profética y utópica de América, en la cual el Caribe funciona como el escenario de la futura superación de toda una serie de antinomias: Europa versus Africa, civilización versus barbarie, historia versus poesía, razón versus pasión.

Aún estando en simpatía con las ideas de Palés, es posible reprocharle su caduco vitalismo filosófico, su dudoso y problemático concepto de "raza", y su intolerable machismo. Por otro lado, el esquema de Palés es obviamente demasidado idealizado y abstracto, y lo que es peor, es demasiado estático: es difícil ver cómola cul tura mulata recién nacida podría evolucionar, desarrollarse y crecer si desde el principio está atrapada en los ciclos inexorables de la temporalidad negra y la producción azucarera de los blancos.

Sin embargo, no fueron éstos los reparos que primero ocasionó la poesía afroantillana de Palés. En cambio, la visión conciliadora y armonizadora de la cultura antillana que proponía Palés escandalizó de primera instancia a la mayoría de los intelectuales de la élite blanca puertorriqueña, quienes rehusaban aceptar al negro como componente étnico importante de la civilización insular y seguían apegados en cambio a una visión hispanofílica de la cultura puertorriqueña. ${ }^{8}$ Este escándalo, este efecto corrosivo de la visión de Palés con respecto a la hispanofilia, parecería ser uno de los pocos elementos de la obra palesiana que rescatan Ana Lydia Vega y los principales escritores puertorriqueños de hoy, pues en lo demás, éstos parecen diferir bastante del poeta guayamés. Por ejemplo, los actuales autores puertorriqueños han optado casi todos por la prosa -el vehículo por excelencia de la crítica- en vez del verso, y en vez de las generalizaciones metafísicas a las que Palés era dado,

\footnotetext{
7 Palés, "Mulata-Antilla”. Obras: 1914-1959. Tomo I: Poesta 515-16.

${ }^{8}$ Véase el análisis de esa controversia hecho por Arcadio Díaz Quiñones en "Tomás Blanco: racismo, historia, esclavitud", estudio preliminar a Tomás Blanco, El prejuicio racial en Puerto Rico (Río Piedras: Ediciones Huracán, 1985) 29-34.
} 
prefieren analizar las particularidades y las contradicciones de la realidad caribeña concreta ayudándose con los discursos de la sociología, la semiótica y el periodismo.

Pero los textos de Vega, en particular, están mucho más cerca de los de Palés de lo que a primera vista pensariamos. Para empezar, podemos observar que tres de los cuentos de Encancaranubladollevan epígrafes sacados de Tuntún de pasa y grifería. ${ }^{9}$ Por otro lado, los relatos de Encancaranublado se ocupan de sucesos y personajes de toda la región caribeña. Haitianos, cubanos, dominicanos y puertorriqueños, así como habitantes de las Antillas Menores y Jamaica, pueblan estos relatos de manera similar a como aparecen en la poesía afroantillana de Palés. También, como en Tuntún, muchos de los personajes de Vega son negros o mulatos, y tienden hacia el estereotipo y la caricatura.

Recuérdese, por ejemplo, el relato que le da su título a la colección. La situación narrativa de "Encancaranublado" se parece a la de aquellos chistes étnicos tan conocidos, en los que un americano, un ruso y un puertorriqueño, por ejemplo, se encuentran y comparan las virtudes relativas de sus países, pero también se asemeja a poemas de Tuntún como "Canción festiva para ser llorada" en el que el "Yo" poético palesiano realiza un amplio periplo descriptivo por las Antillas, personificándolas y caracterizándolas ("Cuba: ñañigo y bachata; Haití: vodú y calabaza; Puerto Rico: burundanga"). En este caso, los tres personajes principales son emigrantes ilegales y náufragos de Haití, Santo Domingo y Cuba. Éstos, tratando de llegar a los Estados Unidos, acaban reunidos en el mismo botecito en al ta mar. Allí, en vez de unir sus esfuerzos, reproducen los conflictos y prejuicios que dividen a sus respectivos países, haciendo zozobrar la embarcación. Por casualidad, los rescata un barco de la marina de guerra norteamericana, en la cual los náufragos descubren que todo el trabajo sucio bajo cubierta lo hacen los puertorriqueños, y que a ellos les espera el mismo destino.

Los personajes de este cuento son estereotipos nacionales sin mayor elaboración, situados en el contexto de una alegoría política: el haitiano Antenor, el dueño original de la embarcación (¿como los haitianos, que fueron los primeros antillanos en independizarse?), es pobre y se encuentra aislado por su desconocimiento del español; el dominicano Diógenes, por su parte, habla español con toda una serie de gritos típicamente quisqueyanos y desprecia a los haitianos; el cubano Carmelo es avispado, jactancioso y agresivo, y su habla también está salpicada abundantemente de cubanismos. No hay intento alguno de dotarlos de una psicología detallada y verosímil; se trata simplemente de figuras emblemáticas que se mueven dentro de una trama patentemente alegórica. Como las figuras de un auto sacramental, los personajes de

\footnotetext{
${ }^{9}$ En "El jueguito de la Habana" se citan versos de "Canción festiva para ser llorada"; en "Contrapunto haitiano" los versos citados son de la "Elegía del Duque de la Mermelada" y en "Otra maldad de Pateco" los versos palesianos provienen de "Falsa canción de baquine".
} 
"Encancaranublado" son activados por una fuerza superior a ellos mismos; en este caso, esa "fuerza superior" es la voluntad de la propia autora, cuya voz narrativa llena de giros poéticos y coloquiales y de expresiones intercaladas en inglés y francés mueve la trama inexorablemente hacia su conclusión predeterminada.

De hecho, otro rasgo palesiano de los cuentos de Vega es su tendencia a la alegoría y la parábola para representar de una manera condensada e impactante -aunque también algo dogmática - temas y problemas que de otro modo requerirían volúmenes enteros de discusión detallada. Además del cuento "Encancaranublado", otros relatos que entrañan obvias alegorias políticas, culturales, o sociales en el libro son: "Puerto Rican Syndrome", "El Senador y la Justicia", Otra maldad de Pateco", e "Historia de arroz con habichuelas". En todos estos relatos, los personajes son estereotipos, caricaturas o entes personificados cuyas mutaciones e interacciones ilustran una moraleja que unas veces se nos anticipa en los epígrafes y otras se nos presenta de manera más tradicional al final del cuento. Así sucede, por ejemplo, en "Historia de arroz con habichuelas", cuya moraleja nos es dada en verso, como en las fábulas dieciochescas de Samaniego o en los relatos medievales del príncipe don Juan Manuel:

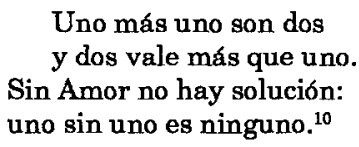

Pero, según puede verse en esta moraleja, la alegoría en los cuentos de Vega no es sólo una suerte de taquigrafía narrativa, sino que, como en los poemas de Palés, se convierte en la base para una "ficción de concordia" (según la expresión acuñada por Frank Kermode), ${ }^{11}$ una visión utópica de la reconciliación de opuestos, un llamado a la unidad y al consenso.

Otra de las formas en que Vega trata de lograr una concordia discors caribeña es en su uso del lenguaje, en su estilo, el cual también nos recuerda a Palés en el hecho de que ambos estilos consisten de amalgamas de vocablos y giros caribeños. La amalgama lingüística de Vega es más hospitalaria al inglés y al francés que la de Palés, pero en ambas se manifiesta el sueño utópico de una lengua pan-caribeña, de un idioma que podria empezar como un pidgin o un bêche-de-mer, un idioma comercial, lleno de barbarismos y vulgarismos, pero que acabaría convirtiéndose en un vehículo refinado de expresión literaria común a todo el Caribe. Es interesante contrastar, en este sentido, la actitud

10 Vega, Encancaranublado 140.

${ }^{11}$ FrankKermode. The Sense of an Ending. Studies in the Theory of Fiction (Londres: Oxford University Press, 1966) 59 y ss. 
integradora ante el lenguaje popular que exhibe Ana Lydia Vega en sus relatos con la actitud "apocalíptica" de Luis Rafael Sánchez en La guaracha del Macho Camacho. ${ }^{12}$ A diferencia de los personajes de Sánchez-La China Hereje, doña Chon, Vicente Reynosa, graciela Alcántara, y sobre todo Benny-, quienes apenas pueden expresarse con propiedad y fluidez debido a que su idioma y sus procesos mentales están interferidos por los medios de masa, los personajes de Vega (que a menudo son también los narradores) son por lo general muy elocuentes, y se expresan con abundancia, entusiasmo y eficacia en su lenguaje mixto y degradado, como lo hace el narcómano narrador de "Cráneo de una noche de verano":

Pa colmo e madre, le había dao con eslembarse frente al espejo del baño como si le estuvieran pasando a él solito una rica película $\mathrm{X}$ desas que dan en el lorraine. Cuando rompieron a aparecérsele monstruos pa tos los gustos se le pusieron los güevos bajo cero, men. Y cuando le salió su propia careta toa blanca y flaca y arrugá - el que era tofe, prieto y todavía no habia votao en unas elecciones- pa qué te cuento, mano. ¿Tư sabe los que es verse a uno mismo jincho y mas plegao que un culo y tras de plegao sin dientes? Chacho, deja eso. Le dio una canillera de ocho cilindros de las que ponen a chillar a uno como lechón en víspera e Reyes. ${ }^{13}$

Pero si Vega está muy cerca de Palés en su uso de alegorías y amalgamas lingüísticas para producir una impresión de armonía caribeña en muchos de sus relatos, no es menos cierto que Vega se aleja de Palés, como ya indicamos antes, al aludir en otros cuentos a particularidades socioeconómicas concretas del Caribe, particularidades que tienden a poner en duda la visión utópica de la unidad caribeña. El ejemplo más claro de esto lo es el cuento "Jamaica Farewell", en el que se contrasta la retórica rimbombante de los delegados a un Congreso para la Unidad Caribeña convocado por los Estados Unidos en Jamaica con la cruda realidad de la pobreza y el crimen en las calles de Kingston. Un interés semejante por la realidad caribeña concretamente lo encontramos en cuentos de Encancaranublado como "El día de los hechos", "El jueguito de La Habana" y "Contrapunto haitiano". En el primero se describe una cadena de venganzas entre haitianos y dominicanos, producto de una larga historia de abusos y rencores mutuos entre ambas naciones. En el segundo, se intenta retratar la mentalidad de una mujer del exilio cubano, y en el tercero se representan las diferencias de clase que dividen y oprimen a los haitianos.

12 Tomo prestados los términos que utiliza Umberto Eco para describir las dos actitudes distintas adoptadas por los intelectuales ante el fenómeno de la cultura de masas. Unos, los "integrados", la ven como algo positivo y "normal" para la cultura moderna; los "apocalipticos", en cambio, la ven como una fuerza que puede destruir la alta cultura y la particularidad étnica por igual. Véase: Apocaltpticos e integrados ante la cultura de masas (Barcelona: Editorial Lumen, 1968).

${ }^{13}$ Vega, Encancaranublado 82. 
Vega también se aleja de Palés al problematizar la metáfora de la "mulataantilla". Para Vega, por razones evidentes, la mujer antillana no es un emblema unificador y abstracto, sino un ser histórico y concreto. Más aún, la mujer aparece en Vega como un ente tan escindido y problemático como el Caribe mismo. Piénsese en el caso — sin duda caricaturesco- de la "neorican" Suzi Bermiúdez en el cuento "Pollito Chicken" de Vírgenes y mártires, quien narra su relato en un español entreverado de inglés (o vice-versa) y no sabe si es norteamericana o puertorriqueña. $O$ mejor aún, en la figura terrible y ambivalente de Mama Yona en el relato "Ahí viene Mama Yona" (también de Vírgenes y mártires).

"Ahí viene Mama Yona" cuenta los preparativos que se hacen en la casa familiar de la narradora adolescente cuando se anuncia la inminente visita de la abuela, Mama Yona. ${ }^{14}$ Esos preparativos (narrados en tono burlonamente apocalíptico) consisten primeramente en limpiar con minuciosidad hasta el último rincón de la casa. Luego la madre de la narradora procede a borrar toda huella de la ideología independentista de ésta:

Entonces mi madre irrumpe en los cuartos como un ángel exterminador, a arrancar carteles comprometedores, a borrar consignas de las paredes, a esconder, por encima de mis débiles protestas, las banderas de Puerto Rico y Lares. Albizu Campos y Betances aterrizan de cabeza en el baúl. Patria o Muerte pierde la Patria. ${ }^{15}$

Pero la madre también procura ocultar la afiliación de su esposo y de otros parientes al espiritismo y al autonomista Partido Popular Democrático, los cuales tampoco son del agrado de Mama Yona. El cuento tiene lugar en los finales de la década del setenta, cuando se encontraba en el poder el Partido Nuevo Progresista (el cual propugna la anexión de Puerto Rico a los Estados Unidos) y se había desatado una persecución contra los partidos políticos opositores y una campaña intensa en los medios de masa para promover la estadidad ante la opinión pública. Las prohibiciones que dictamina la madre a raíz de la visita de Mama Yona aluden bastante directamente a esa circunstancia histórica:

Proceden a leernos la cartilla de los temas intocables: alusiones claras o solapadas al honorable morador de Fortaleza, a su hípico apelativo o a su importada mitad; socarronerias abiertas o veladas en torno al sacrosanto ideal de la estadidad federada 0 a nuestros arios conciudadanos del Norte; referencias a desempleo, cupones, criminalidad, corrupción administrativa, persecución política, status; mención de la palabra patria o de la aún más obscena nación; blasfemias sanas o alevosas contra la Santa Madre Iglesia Católica Apostólica

\footnotetext{
${ }^{14}$ Virgenes y mártires 119-123.

1s Virgenes y mártires 119.
} 
Romana y/o la curia universal; lenguaje soez o refranerías de mal gusto; toda insubordinación oral, 6ptica o gestual frente al dictamen matriarcal; cualquier pregunta que manifestare una curiosidad malsana u ociosa y osare revelar la pava oculta en el corazón muñocista de nuestros progenitores. ${ }^{16}$

La razón de todas estas precauciones es doble: por un lado, la abuela posee tierras y dinero que dejará en herencia sólo a los parientes que comulguen con sus ideas, y por otro, la abuela soborna a su parentela citadina con toda una cornucopia de frutas y comidas típicas del campo que ella cocina mejor que nadie.

Aunque el modelo literario de Mama Yona es obviamente la Mamá Grande de Gabriel García Márquez, este personaje de Vega está transido por una ambivalencia que no se percibe en aquél. La ambivalencia reside en parte en el hecho de que Mama Yona, aunque opresiva, es también un emblema de la prosperidad y la abundancia; pero además -y esto es quizá más importante-también reside en el hecho de que Mama Yona es una matriarca y que el cuento "Ahí viene Mama Yona" pertenece a un libro de tendencia abiertamente feminista. Estamos entonces - aunque parezca paradójico- ante un relato anti-matriarcal escrito por una feminista. ¿Cómo se explica esto?

De primera instancia, la actitud ambigua de Vega ante la figura de la madre puede explicarse en términos de la teoría feminista. Recientemente, el psicoanálisis y la crítica literaria feminista han revisado algunas de las nociones al uso acerca de cómo la mujer desarrolla su identidad. Según las teorías de Nancy Chodorow, por ejemplo, la mujer deriva su identidad de la identificación con su madre; pero esta identificación, a diferencia de la que ocurre entre el varón y su padre, es inherentemente ambigua: a menudo hay un conflicto entre la identificación con los aspectos admirables de la madre como ser humano y un rechazo de su carácter de víctima del patriarcado. ${ }^{17}$ Como observa Judith Kegan Gardiner:

The most disturbing villain in recent women's fiction is not the selfish or oppressive male but instead the bad mother. This mother-villain is so frightening because she is what the daughter fears to become and what her infantile identifications predispose her to become. One way in which the author may dispose of this fear is by rendering the mother so repulsive or ridiculous that the

${ }^{16}$ Virgenes y mártires 120 . La Fortaleza es la residencia del Gobernador de Puerto Rico; lo de "hípico apelativo ... importada mitad" se refiere al mote de "El caballo" aplicado al entonces Gobernador, Carlos Romero Barceló, quien estaba casado con una norteamericana. La "pava ... corazón muñocista" son alusiones al Partido Popular Democrático y a su fundador. La "pava", elemblema delPPD es el sombrero típico del campesino puertorriqueño y el fundador del PPD fue Luis Muñoz Marín.

${ }^{17}$ Nancy Chodorow, The Reproduction of Mothering (Berkeley: University of California Press, 1978). 
reader must reject her as the fictional daughter does. Another tactic is for the author to kill the mother in the course of the narrative. ${ }^{18}$

Más allá de esta fundamental repulsión de la "madre malvada", sin embargo, bien podría verse desde una perspectiva feminista a Mama Yona esa matriarca anticomunista y proyanqui que sin embargo es dueña y señora de los secretos de la cocina criolla - como una reescritura crítica, y más fiel a la realidad histórica de la "mulata-antilla". Recuérdese que en la visión machista de Palés, la "mulata-antilla" es a la vez la encarnación de la libertad antillana y de los arquetipos de la Gran Madre fecunda y de la Amante complaciente, quien le brinda al poeta los "frutos del trópico" en "la clara bahía" de su cuerpo. En el poema de Palés el ideal de libertad nacional y armonía social, aunque se enmascara de amor, está cimentado sobre la desagradable escena patriarcal de un hombre blanco mirando a su corteja mulata y viéndola como un manjar apetitoso. Vega, en "Ahí viene Mama Yona”, ve a la colosal figura de la "mulataantilla" como un emblema de la opresión social y política que la mujer puertorriqueña padece y de la que a veces se vuelve cómplice.

De que Mama Yona es la "mulata-antilla" revisada y puesta al día no cabe duda, una vez que se leen las siguientes líneas del cuento:

Entre gritos, aplausos y el espionaje más o menos flagrante de los vecinos, desciende Mama Yona, precedida por sus tetas planetarias y escoltada por su respetable señor culo; de medio luto, como desde que la conocemos, su cabeza de alcurniosa mulata cabalgada por el eterno e insolente moño. ${ }^{19}$

Más aún, como la "mulata-antilla" palesiana, Mama Yona viene cargando con "todos los frutos ... del trópico": nísperos, anones, corazones, quenepas, lerenes, gandules, así como platos típicos de la cocina criolla: buñuelos, pasteles de yuca, pasteles de arroz, pan de maíz, etcétera. Los "frutos" y golosinas que Mama yona ofrece a su parentela en abundancia son los instrumentos con los cuales ejerce su opresión, pues son la desviación de la libertad, la solidaridad y el amor hacia los canales más inofensivos (para el sistema que Mama Yona representa) del egoísmo y del placer alimenticio.

En este cuento, Vega parece sugerir que si el discurso del nacionalismo es patriarcal, el del anexionismo es esencialmente matriarcal. Significativamente, es la madre de la narradora ("La Mater", como la llama ella), quien coordina la operación de censurar los emblemas independentistas que hay en la casa, incluyendo los retratos de los próceres Pedro Albizu Campos y Ramón Emeterio Betances. Por otro lado, sin embargo, la afiliación de Mama Yona a la Iglesia Católica parecería a primera vista inconsistente con su anexionismo. Más

\footnotetext{
${ }^{18}$ Judith Kegan Gardiner. "On Female Identity and Writing by Women", Critical Inquiry. Writing and Sexual Difference 2 (Invierno de 1981) 356.

${ }^{19}$ Virgenes y mártires 123.
} 
consistente quizá hubiera sido imaginarla devota de alguna secta protestante, las cuales en su mayoría llegaron a la isla por vía de los Estados Unidos. Es bueno recordar, empero, que si bien muchos nacionalistas puertorriqueños eran fervientes católicos - lo cual era un signo de su conservadurismo cultural--, el número de católicos anexionistas siempre ha sido superior. No obstante, la coherencia de la alusión en este caso no reside sólo en su adecuación al contexto histórico, sino también al hecho de que reitera una vez más la simbología matriarcal: se trata, después de todo, de la "Santa Madre Iglesia". La asociación entre anexionismo y matriarcado también se ve sugerida por el vínculo de ambos conceptos con el sustento, con la alimentación; las golosinas que ofrece Mama Yona son el equivalente de los cupones de alimentos y el welfare por medio de los cuales el gobierno de los Estados Unidos ayuda al gobierno insular a paliar las realidades coloniales del desempleo y la pobreza.

La posición de Vega en el debate acerca de la nacionalidad puertorriqueña es pues similar a la de otras intelectuales y luchadoras feministas a lo largo de la historia de Puerto Rico, desde Luisa Capetillo hasta Julia de Burgos y Nilita Vientós Gastón. Como ellas, Vega intenta reconciliar la lucha por la independencia y la autodefinición nacional con la lucha contra el discrimen sexual. Pero también como ellas Vega se enfrenta con la alarmante posibilidad deque tal vez no se pueda adelantar el discurso feminista sin criticar severamente -y quizás debilitar- el discurso independista, el cual es profundamente patriarcal..$^{20}$ En última instancia, la pugna entre patriarcalismo y feminismo aparece en la obra de Vega como otra de las divisiones que polarizan la sociedad puertorriqueña, dificultando su unidad.

A lo largo de sus cuentos, Vega lucha por presentar una solución positiva al problema de la unidad o multiplicidad caribeña, al intentar asimilar y trascender el discurso patriarcal de la poesía de Palés Matos. Como Palés, Vega sueña con unas Antillas libres, unificadas, y limpias de racismo, pero más aún,

${ }^{20}$ No he hallado ningún trabajo en el que se discuta abiertamente y en detalle esta cuestión; sin embargo, la conciencia de este problema aflora de vez en cuando en casi todas las feministas puertorriqueñas al escribir sobre la participación política de la mujer. Como dato curioso, vale apuntar que, según Norma Valle, muchas de las organizaciones de mujeres que han surgido en Puerto Rico a lo largo de este siglo - desde las sufragistas de los años 20 y 30 hasta los grupos sindicales en décadas más recientes-han sido de corte anexionista o por lo menos no se han pronunciado en torno a la independencia. Véanse los comentarios de esta autora en " $\mathrm{El}$ feminismo y su manifestación en las organizaciones de mujeres en Puerto Rico", en La mujer en la sociedad puertorriqueña, editado por Edna Acosta-Belén (Río Piedras, P.R.: Editorial Huracán, 1980) 91-107. También véase la "Introducción" de Acosta-Belén, 22. Puede consultarse además con provecho el tomo

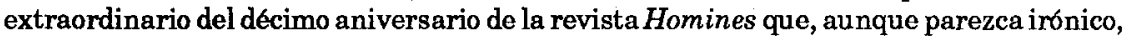
está dedicado integramente a la mujer: Mujeres puertorriqueñas, protagonistas en el Caribe. Homines. Revista de Ciencias Sociales 4 (Universidad Interamericana de Puerto Rico, 1987). 
limpias de discrimen sexual. Vega sueña con una noción armonizadora de la nacionaldad puertorriqueña fundada en la integridad psíquica y cultural de los hombres y mujeres de su país. Pero al hacer sus planteamientos armonizadores en forma narrativa, Vega les resta fuerza, pues loque más resalta en sus cuentos es su aspecto crítico. En ellos todavía aparecen los hombres y mujeres antillanos divididos entre sí y fragmentados en su fuero interno, como la región en la que viven. El hecho mismo de que Vega haya decidido presentar su reflexión sobre el Caribe en forma de un libro de cuentos estructurado a base de metáforas meteorológicas (y la meteorología, recordémoslo, es una ciencia que trabaja a base de probabilidades, no de certezas absolutas) sugiere que ésta no debe considerarse su última palabra sobre el asunto. Ante los inciertos tonos grises de un cielo encancaranublado, Ana Lydia Vega prefiere reservarse su pronóstico, quizá porque ha entendido la lección de Borges en "El jardín de senderos que se bifurcan" de que el porvenir siempre es plural. 